\title{
A Comparison of the Technical Quality of American and Japanese Ranitidine Tablets
}

\author{
Makoto Otsuka', Yuka Akizuki², Kuniko Otsuka ${ }^{3}$, \\ Shinichiro Yanagisawa ${ }^{4}$, Isao Kamae ${ }^{4}$, and James A. Jorgenson ${ }^{5}$ \\ 'Research Institute of Pharmaceutical Sciences, Faculty of Pharmacy, Musashino University, \\ Shinmachi 1-1-20, Nishi-Tokyo, Tokyo 202-8585, Japan. \\ 2Kobe Pharmaceutical University, Motoyama-Kitamchi 4-19-1, Higashi-Nada, Kobe 658-8558, \\ Japan. \\ ${ }^{3}$ School of Medicine, Showa University, Hatanodai 1-5-8, Shinagawa, Tokyo 142-8555, Japan. \\ ${ }^{4}$ Faculty of Medicine, Kobe University, Kusunokichou 7-5-1, Chuo, Kobe 650-0017, Japan. \\ ${ }^{5}$ University Hospital Pharmacy, University of Utah, 50 North Medical Drive, Salt Lake City, \\ Utah 84132, USA.
}

\begin{abstract}
The purpose of this study was to compare the technical quality of commercial American and Japanese ranitidine tablets. Five brands of 150-mg USP tablets and six brands of 150-mg JP tablets were compared on hardness, friability, average weight, average content, content uniformity, and dissolution.

The difference in hardness between American and Japanese tablets was significant. Dissolution profiles of Japanese tablets were not significantly different from one other, whereas those of American tablets were significantly different. However, all brands complied with USP 27. Since all brands can be expected to be in therapeutic use, this result supports the use of the USP criterion as an indicator for therapeutic efficacy.
\end{abstract}

\section{Introduction}

ince generic drugs are safe, effective, and lower cost, they have many advantages from a medical-financial viewpoint. However, there must be assurance that generic drugs on the market are quality products. Since there is risk in the selection of generic drugs by the pharmacy or hospital for use by consumers and healthcare professionals, it is important to ensure that safe, effective, high quality, and equivalent generic products are available. Therefore, proof of safety and effectiveness is required before generic drugs can be used. The dissolution test is a method of testing the release of active ingredients from oral solid preparations and is aimed at confirming their quality according to a fixed standard, which also aids in preventing significant bioinequivalence $(1,2)$. For the approval of a generic drug in the United States, bioequivalence to the brand-name drug is satisfied by showing that an acceptable in vitro dissolution standard is met (3). Since 1999, the Japanese Orange Book (4) has been published by the Society of Japanese Pharmacopoeia to specify the quality of Japanese products. There are many reports on quality control of generic drugs with dissolution tests (5). While international pharmaceutical harmonization has been promoted, for example, through the "International Conference on Harmonization (ICH) of Technical Requirements for the Registration of Pharmaceuticals for Human Use in Japan, the United States, and the European Union" (6-8), there are reports concerning the comparative studies of the quality of generic drugs between different countries.

Ranitidine belongs to a class of drugs known as $\mathrm{H} 2$-blockers, which block the action of histamine on stomach cells, thus reducing stomach acid production (1). The difference in dissolution behavior between innovator and generic ranitidine tablets has been previously reported (9). In a previous study, the quality of American and Japanese ibuprofen tablets was compared (10); in the present study, the quality of American and Japanese ranitidine tablets is compared, including the innovator product and generics.

\section{Experimental \\ Materials}

Five types of 150-mg USP ranitidine tablets and six kinds of 150-mg JP tablets were purchased. Information on these tablets is summarized in Table 1. All samples were stored at room temperature, and all tests were performed within product expiration dates.

Ranitidine hydrochloride reference standard (Lot No.SER 7018) was purchased from Wako Pure Chemicals Co. Ltd., Tokyo, Japan.

The quality requirements for ranitidine immediaterelease tablets in the United States and Japan are as follows:

In USP 27:

Uniformity of Dosage Units: The amount of active ingredient is between 85 and $115 \%$ and the 
Table 1. Tablets included in the study.

\begin{tabular}{|c|c|c|c|c|c|}
\hline Code & Brand & Package & Lot & exp. & Company \\
\hline JAPAN-A & Zantac tablet & PTP & ED1F2 & 2005.04 & GlaxoSmithKline \\
\hline JAPAN-B & Ranitac150 & PTP & E123A1 & 2005.06 & Nichi-Iko Pharmaceutical Company \\
\hline JAPAN-C & Hattosuka Tab150 mg & PTP & $\mathrm{CHO4}$ & 2004.06 & Ohara Pharmaceutical \\
\hline JAPAN-D & Ranimerck Tab150 & PTP & 001AH5 & 2005.04 & Merck-Seiyaku \\
\hline JAPAN-E & Raden Tab150 & PTP & 2501 & 2005.06 & Sawai Pharmaceutical Co., Ltd. \\
\hline JAPAN-F & Ranichizan Tab150 & PTP & B77 & 2004.05 & Nihon Pharmaceutical Industry Co., Ltd. \\
\hline USA-A & Zantac150 & PTP & 1ZP0786 & 2003.03 & Glaxo Wellcome Inc. \\
\hline USA-B & Ranitidine Tablets, USP & PTP & 131360 & 2003.07 & Geneva Pharmaceuticals, Inc. \\
\hline USA-C & Ranitidine Tablets, USP & Bottle & GA5354 & 2003.09 & Apotex Corp. \\
\hline USA-D & Ranitidine Tablets, USP & Bottle & $123747 \mathrm{~A}$ & 2003.05 & Novopharm USA Inc. \\
\hline USA-E & Ranitidine Tablets, USP & Bottle & M256 & 2003.07 & MAJOR Pharmacruticals, Inc. \\
\hline
\end{tabular}

relative standard deviation (RSD) is less than or equal to $6.0 \%$.

Dissolution test: Not less than $80 \%$ of the labeled amount of ranitidine is dissolved in $45 \mathrm{~min}$. In JP 15:

Uniformity of dosage units: The acceptance value (AV) of the preparation is less than $15 \%$.

Dissolution test:There is no specification yet.

\section{Dissolution}

The dissolution profiles of the tablets were investigated using two dissolution apparatus (Toyama Sangyo, Japan) containing 3 rotors and vessels with 6 glass-fiber probes at each flask, linked to a UV spectrophotometer (Photal Otsuka Electronics, Japan). The glass-fiber probes (6 $\mathrm{mm}$ in diameter) were fixed at various locations in the flask. USP Apparatus 2 paddles were used for the dissolution test at $50 \mathrm{rpm}$ for $50 \mathrm{~min}$. The dissolution medium was $900 \mathrm{~mL}$ of distilled water at $37.0 \pm 0.5^{\circ} \mathrm{C}$ in a $1000-\mathrm{mL}$ covered round-bottom flask. The sample tablets were introduced into $900 \mathrm{~mL}$ of water in the flask, and the UV absorbance was measured every minute by the two-wavelength method (calculated at $350 \mathrm{~nm}$, corrected at $410 \mathrm{~nm}$ ). Absorbance values collected automatically were converted to percentages of tablet dissolved by dividing by the standard UV absorbance. Statistical tests were carried out using the analysis of variance procedure (ANOVA).

\section{Content Uniformity}

Ten sample tablets were randomly selected, and the following process was repeated ten times. A tablet was introduced into $900 \mathrm{~mL}$ of distilled water in a flask, and the solution was agitated at $300 \mathrm{rpm}$ by a mixer for $60 \mathrm{~min}$.
Ten milliliters of the sample solution was filtered through a 0.8- $\mu \mathrm{m}$ membrane filter, the UV absorbance of the solution was measured at $264 \mathrm{~nm}$ (UV 160A, Shimadzu Co. Ltd., Kyoto, Japan), and the drug concentration was calculated based on a calibration curve.

\section{Hardness}

The hardness of the tablets was measured five times using a hardness tester (Toyama Sangyo Co., Osaka, Japan).

\section{Friability}

Twenty tablets were placed into a drum (USP24 and JP14, Toyama Sangyo Co., Ltd, Osaka, Japan), and the drum was rotated at $25 \mathrm{rpm}$ for $5 \mathrm{~min}$ following USP 24. The tablets were then placed on a No. 10 mesh sieve, and any loose dust was removed with a soft brush and weighed.

\section{Statistics}

Statcel programs (11) containing a normal distribution test, F-test, Student $t$-test, Welch's $t$-test, Mann-Whitney's $U$-test, Bartlett test, one-factor analysis of variance test (ANOVA), and Kruskal-Wallis test were used as statistical data analysis methods.

\section{Results \\ Physical Parameters}

Table 2 shows the weight variation of American and Japanese ranitidine tablets. The average tablet weights of American tablets were between 0.3235 and $0.2200 \mathrm{~g}$, but those of the Japanese were consistently close to $0.25 \mathrm{~g}$. The relative standard deviations $\left(\mathrm{RSD}_{\mathrm{w}}\right)$ for American tablet weight variation are between 0.777 and 2.468 , but 
Table 2. Weight Variation and Tablet Friability.

\begin{tabular}{lllll}
\hline & Average, $g$ & $\mathrm{~s}$ & $\mathrm{RSD}_{\mathrm{w},} \%$ & $\mathrm{WL}, \%$ \\
\hline UA & 0.3020 & 0.0037 & 1.235 & 0.036 \\
\hline UB & 0.2200 & 0.0043 & 1.932 & 0.048 \\
\hline UC & 0.2409 & 0.0040 & 1.649 & 0.007 \\
\hline UD & 0.3235 & 0.0025 & 0.777 & 0.040 \\
\hline UE & 0.2405 & 0.0059 & 2.468 & 0.021 \\
\hline JA & 0.26537 & 0.040597 & 15.30 & - \\
\hline JB & 0.2512 & 0.0033 & 1.319 & 0.014 \\
\hline JC & 0.2510 & 0.0014 & 0.540 & 0.021 \\
\hline JD & 0.2505 & 0.0033 & 1.330 & 0.016 \\
\hline JE & 0.2524 & 0.0034 & 1.364 & 0.015 \\
\hline JF & 0.2577 & 0.0023 & 0.874 & 0.033 \\
\hline average & 0.252645 & 0.003876 & 1.53 & - \\
\hline & & & & 0.016 \\
\hline
\end{tabular}

those for Japanese tablets are between 0.540 and 1.715. The range of $\mathrm{RSD}_{\mathrm{w}}$ for Japanese tablet weights is smaller than that of the American tablets, which may be related to the differences in average tablet weight and tablet shape. The weights of the Japanese tablets follow a normal distribution $\left(n=36, \chi^{2}=2.96, p<0.05\right)$, but the American tablet weights do not $\left(n=30, \chi^{2}=49.6, p>0.05\right)$. The average weight of American tablets is not significantly different from that of the Japanese tablets by

Mann-Whitney's $U$-test $\left(n_{1}=30, n_{2}=36, Z=0.1 .78\right.$, $p<0.05$ ).

Figure 1 shows tablet hardness of American and Japanese ranitidine tablets. There are significant differences in hardness by one-factor ANOVA among the American tablets $(F=5.59, p<0.05)$ as well as the Japanese tablets $(F=103.2, p<0.05)$.

Table 2 shows tablet friability. The results suggest that the percentage weight loss (WL) of American and Japanese tablets after the test was below $1 \%$, which is the specification in USP 24 and JP 15.

\section{Drug Content and Drug Content Uniformity}

The drug content of the American tablets was between 103.77 and $106.12 \%$ (Table 3 ), and the average content was $104.59 \%$. The Japanese tablets ranged from 100.68 to $105.81 \%$, and the average was $104.45 \%$. The average drug contents of the American and Japanese tablets were 104.50 and $104.44 \%$, respectively, and were not significantly different from the Japanese by Welch's $t$-test
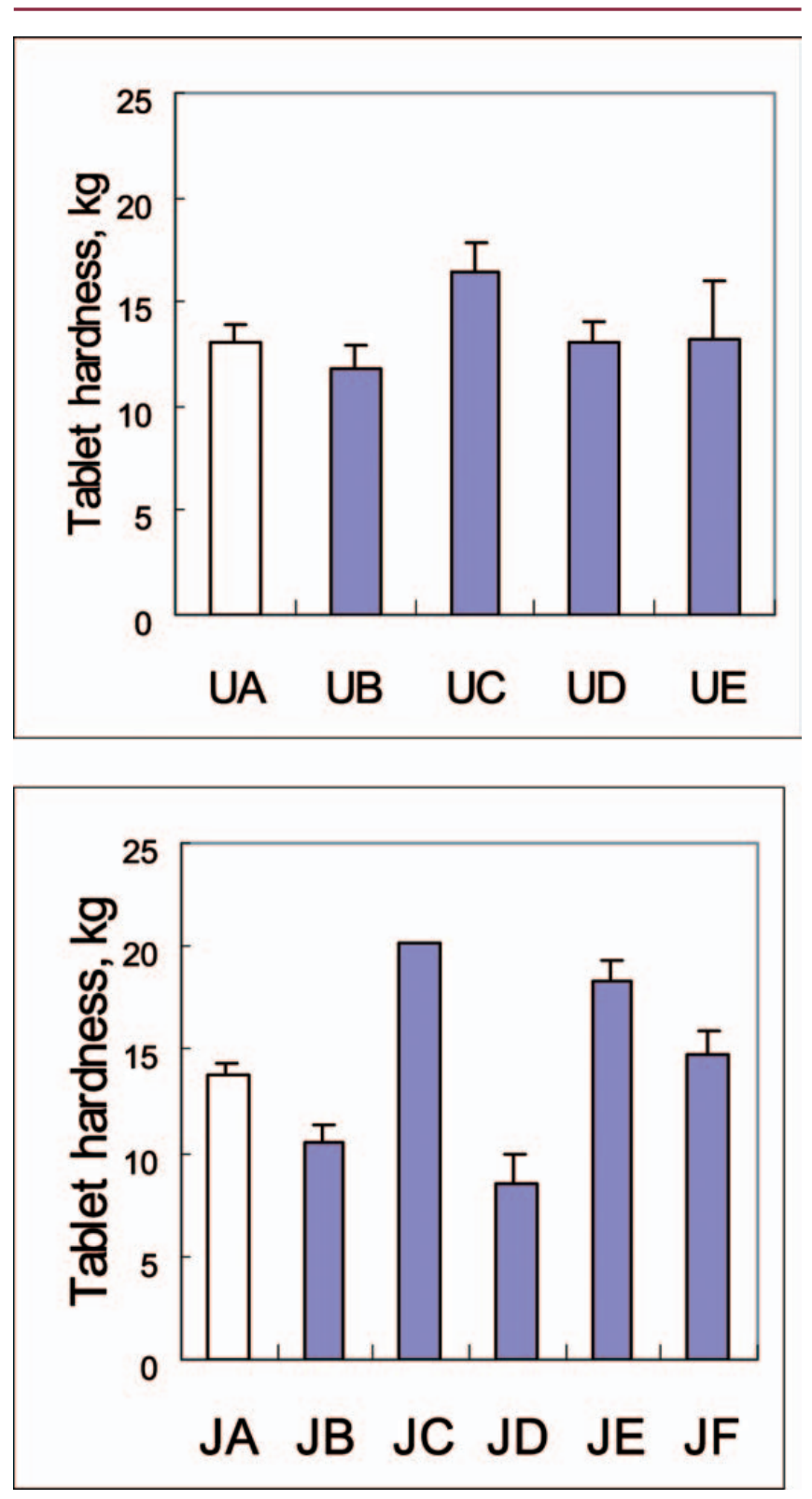

Figure 1. Tablet hardness ( $\pm S D$ ) of American and Japanese ranitidine tablets.

$\left(n_{1}=30, n_{2}=36, t=0.0854, p<0.05\right)$. The AV for $J P 15$ content uniformity test was calculated based on eq 2 and is summarized in Table 3. The RSD for the USP content uniformity test was calculated based on eq 3 following USP 27 and is summarized in Table 1.

$$
s=\sqrt{\frac{\sum_{i=1}^{n}\left(x_{i}-\bar{X}\right)}{n-1}}
$$




\section{Table 3. Uniformity of Dosage Units.}

\begin{tabular}{lccc}
\hline & Content (\%) & RSD & AV \\
\hline UA & 104.30 & 4.82 & 14.90 \\
\hline UB & 106.12 & 5.58 & 18.39 \\
\hline UC & 103.11 & 4.06 & 12.05 \\
\hline UD & 103.77 & 2.58 & 9.45 \\
\hline UE & 105.67 & 2.60 & 11.38 \\
\hline average & 104.50 & 4.11 & - \\
\hline JA & 105.15 & 1.47 & 8.38 \\
\hline JB & 104.75 & 2.44 & 10.13 \\
\hline JC & 104.55 & 1.45 & 7.75 \\
\hline JD & 105.77 & 2.28 & 10.78 \\
\hline JE & 100.68 & 2.72 & 6.66 \\
\hline JF & 105.81 & 2.51 & 11.34 \\
\hline average & 104.44 & 2.73 & - \\
\hline
\end{tabular}

$$
\begin{gathered}
A V=|M-\bar{X}|+k s \\
R S D=\frac{100 s}{\bar{X}}
\end{gathered}
$$

$M$ is label claim (100\%), $\bar{X}$ is the mean of individual contents, $n$ is the sample size, $x_{i}$ is the individual content of the units tested, $k$ is the acceptability constant $(k=2.2)$, and $s$ is the standard deviation.

\section{Dissolution}

Figures 2 and 3 show the dissolution profiles of American and Japanese tablets in distilled water.Tablets $U A$ and $J A$ were the innovator products in the United States and Japan, respectively. The Japanese tablets started to dissolve after 2-3 min, and drug concentrations reached almost $100 \%$ after $20 \mathrm{~min}$. The dissolution profiles of the Japanese tablets are almost identical at all measurement times. On the other hand, the dissolution profiles of the American tablets show a wide range of variability and are significantly different from one other. Figure 4 shows T80 of the American tablets. Since each data set is small $(n=6)$, it was assumed that the data in each group follow a normal distribution. The distributions of T80 of American tablets are significantly different from one other by the Bartlett test (USA, $n=30, \chi^{2}=24.9, p<0.05$ ) and by the Kruskal-Wallis test $(H=25.8, p<0.05)$. The T80 of tablet UA is significantly higher than those of tablets UB, UC, and UE by individual Welch's $t$-test $(p<0.05)$. However, the T80 of

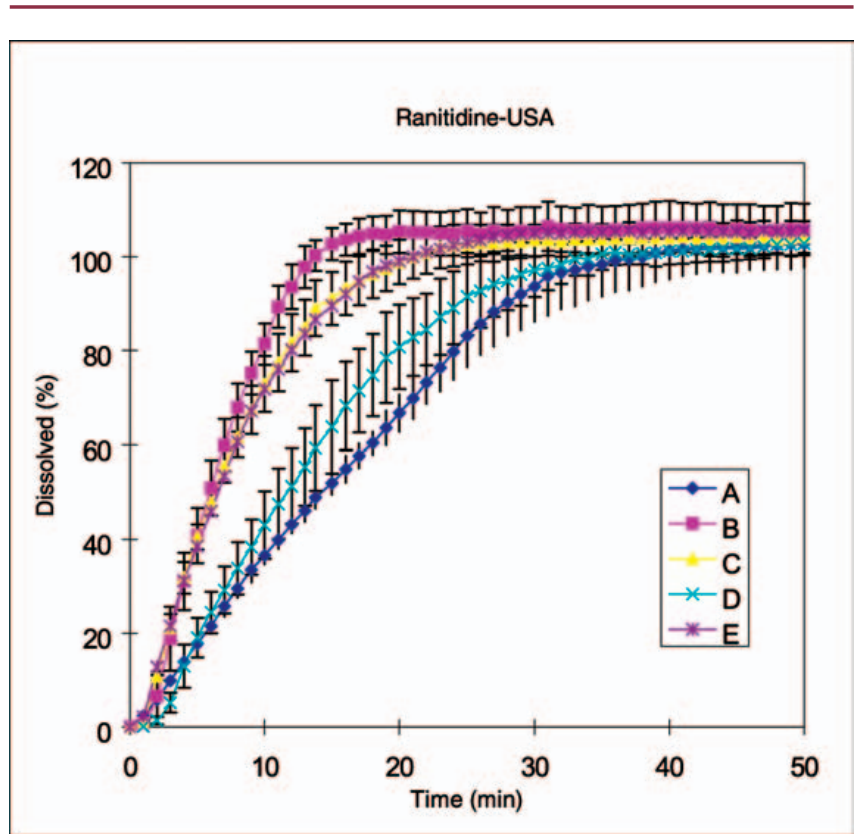

Figure 2. Dissolution profile $( \pm S D$ ) of American ranitidine tablets in distilled water.

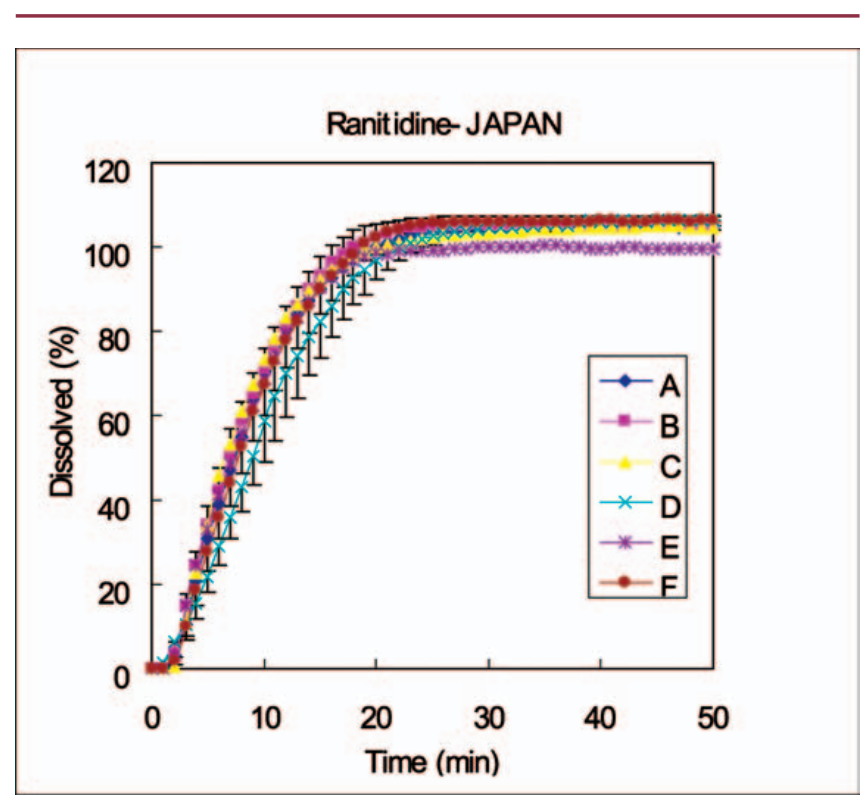

Figure 3. Dissolution profile $( \pm S D$ ) of Japanese ranitidine tablets in distilled water.

tablet UA is not significantly different from the average T80 of American generic tablets (UB, UC, UD, and UE) by Student $t$-test $\left(n_{1}=6, n_{2}=24, t=0.685, p>0.05\right)$.

Figure 5 shows T80 of the Japanese tablets. In contrast, the T80 distributions of the Japanese tablets are not 


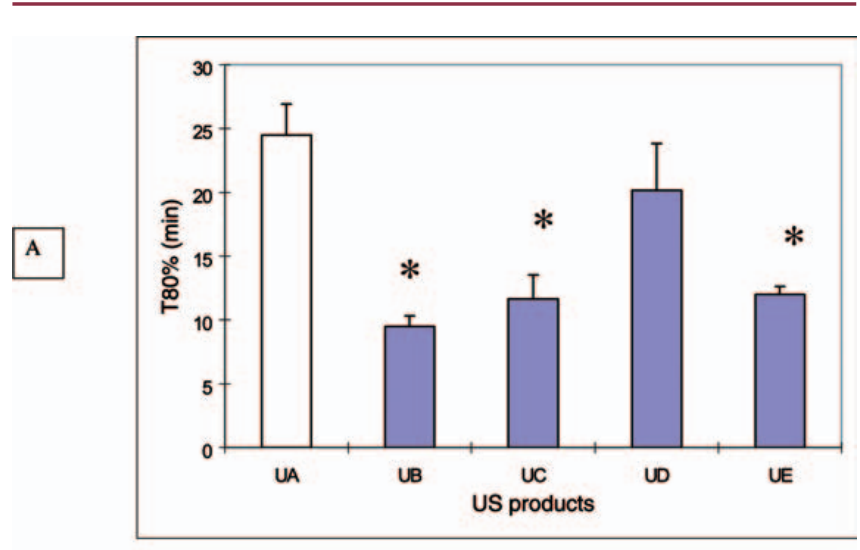

${ }^{*}$ Indicates a significant difference, see text.

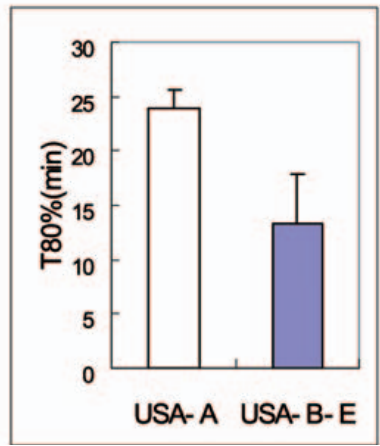

Figure 4. (A) T80 ( $\pm S D$ ) of the American tablets. (B) T80 of the innovator (USA-A) and the average T80 of the USA generics.

significantly different from one other by the Bartlett test (USA, $n=36, \chi^{2}=10.8, p>0.05$ ) and one-factor ANOVA $(F=2.00, p>0.05)$. The T80 of tablet JA is almost the same as that of the average T80 of Japanese generic tablets.

Figure 6 shows the percentage dissolved at $45 \mathrm{~min}$ (A45) of the American tablets. The A45 distributions for the American tablets are not significantly different from one other by the Bartlett test (USA, $n=30, \chi^{2}=4.58, p>0.05$ ) and one-factor ANOVA $(F=1.02, p<0.05)$. The A45 of tablet UA is not significantly different from the average A45 of American generic tablets by Mann-Whitney's U-test $\left(n_{1}=6, n_{2}=24, Z=0.570, p>0.05\right)$.

Figure 7 shows the A45 of the Japanese tablets. The A45 distributions of the Japanese tablets are not significantly different from one other by the Bartlett test (Japan, $n=36$, $\left.\chi^{2}=4.47, p>0.05\right)$. However, the A45 of the Japanese tablets are significantly different from one other by onefactor ANOVA $(F=10.8, p<0.05)$. The A45 of tablet JA is not significantly different from those of tablets JB, JC, JD, and JF by the individual Student $t$-test $(p>0.05)$, but is significantly different from that of tablet JE $(t=5.65$, $p<0.05)$. The difference in tablet JE might be related to drug content difference. The A45 of tablet JA is not
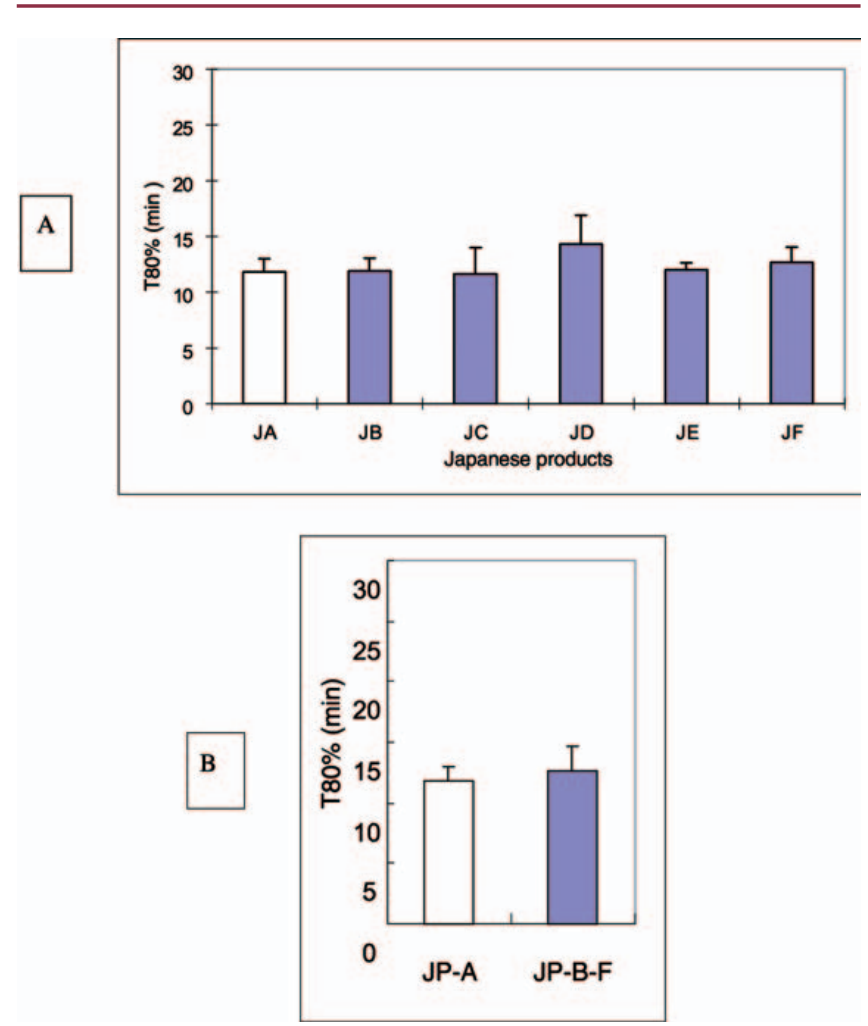

Figure 5. (A) T80 ( \pm SD) of Japanese tablets. (B) T80 of the innovator (JP-A) and the average $T 80$ of the Japanese generics.

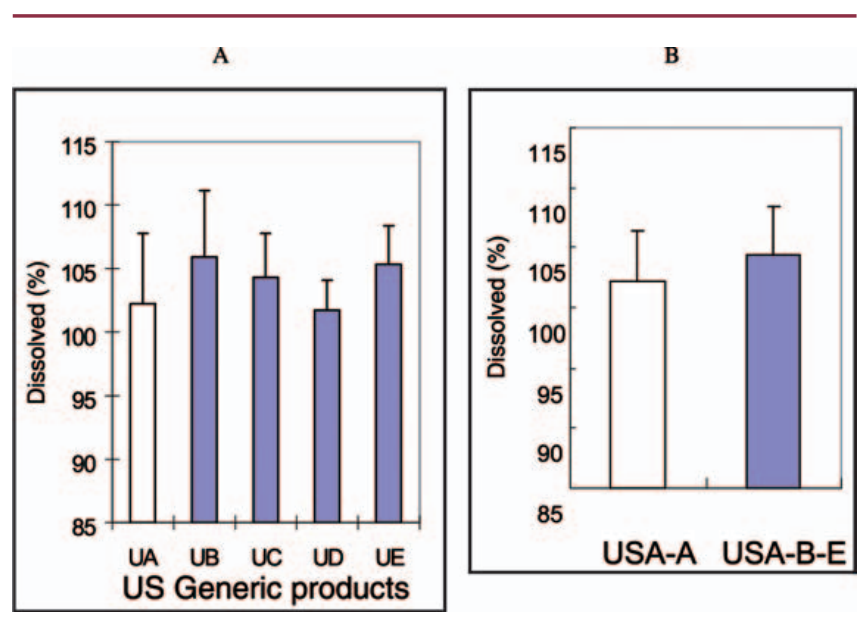

Figure 6. (A) A45 ( $\pm S D$ ) of American tablets. (B) A45 of the innovator (USA-A) and the average $A 45$ of the USA generics.

significantly different from the average A45 of the Japanese generic tablets by the Mann-Whitney's U-test $\left(n_{1}=6, n_{2}=30, Z=0.021, p>0.05\right)$. 
A

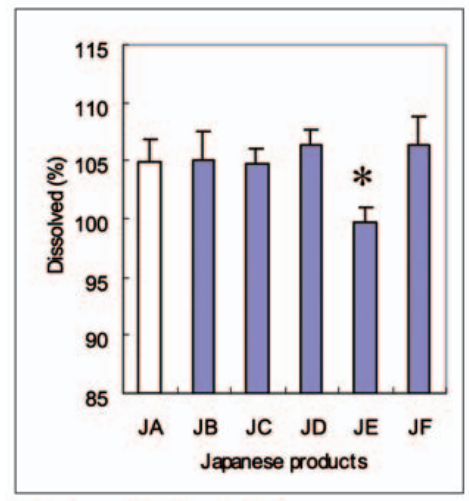

* Indicates a significant difference, see text.

Figure 7. (A) A45 ( $\pm S D$ ) of Japanese tablets. (B) A45 of the innovator (JP-A) and the average $A 45$ of the Japanese generics.

Figure 8 shows the average T80 and average A45 values of the American and Japanese tablets. The T80 of Japanese tablets follow a normal distribution $\left(n=36, \chi^{2}=3.89\right.$, $p<0.05)$, but the American tablets do not $\left(n=30, \chi^{2}=8.87\right.$, $\mathrm{p}>0.05)$. The $\mathrm{T} 80$ of the American tablets is not significantly different from that of the Japanese tablets by the Mann-Whitney $U$-test $\left(n_{1}=30, n_{2}=36, Z=0.837, p>0.05\right)$. On the other hand, the A45 of Japanese and American tablets follows a normal distribution $\left(n=36, \chi^{2}=5.04\right.$, $p>0.05$ and $n=30, \chi^{2}=0.881, p>0.05$, respectively). The distribution of A45 of the American tablets is significantly different from that of the Japanese by the F-test $\left(n_{1}=30\right.$, $n_{2}=36, F=2.519, p<0.05$ ). The A45 of the American tablets is not significantly different from that that of the Japanese by the Welch's $t$-test $(t=0.656, p>0.05)$.

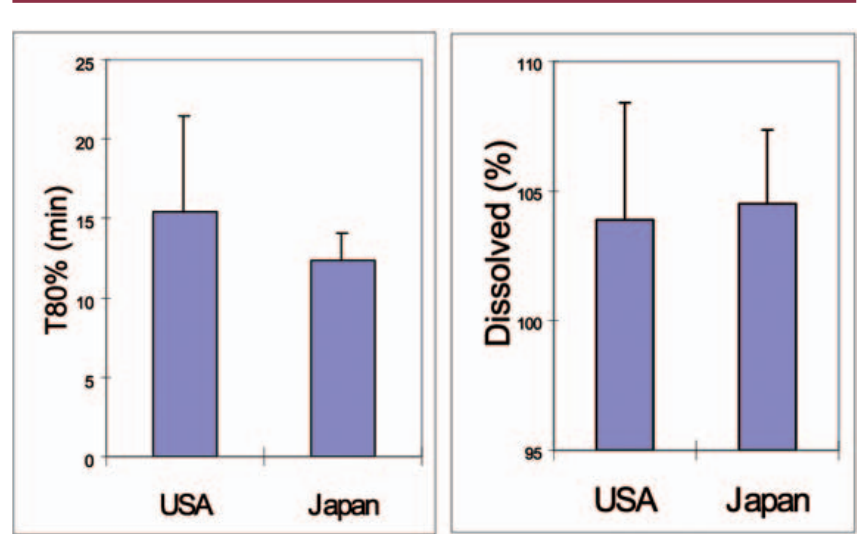

Figure 8. Average T80 and A45 of American and Japanese tablets.

\section{Discussion \\ Physical Parameters, Drug Content, and Drug Content Uniformity}

The tablet hardness results suggest that the hardness of tablets manufactured in both countries is sufficiently high and that there is greater variability among American tablets than among Japanese. The WLs of American and Japanese tablets in a tablet friability test were significantly low. Since ranitidine tablets are film-coated to resist humidity, it seems that the higher mechanical strength may be due to the film coating.

The average weight of the American tablets was almost the same as that of the Japanese, but the $\mathrm{RSD}_{w}$ of all American tablets was about 10 times higher than that of the Japanese. This may be because a direct compression method is commonly used, average tablet weights had a wide distribution between products, or because specific tablet shape was appraised in the United States. However, American tablets were in compliance with the USP.

The average drug content of the American tablets was not significantly different from that of the Japanese. The AVs of all American and Japanese tablet results are within $15 \%$ except for UB. On the other hand, the RSDs of both tablets are less than $6 \%$. The results of the JP 15 content uniformity test indicate that all American and Japanese ranitidine tablets except UB met the JP content uniformity test specification. However, all tablets complied with the USP.This result suggests that the JP content uniformity test is slightly stricter than the USP test.

\section{Dissolution}

Since USP ranitidine tablets require at least $80 \%$ drug dissolution after $45 \mathrm{~min}$, all dissolution profiles were evaluated for T80 and A45. The T80 and A45 of the American tablets were significantly different from one other. In contrast, the dissolution of the Japanese tablets differed only slightly. As ranitidine is very hygroscopic, film-coated tablets are made to resist high humidity and are stored in anti-humidity containers. Anti-humidity coating films resist water penetration and delay tablet dissolution. Since Japan has a climate of heat and high humidity, resistance to humidity is very important and is of concern to preformulation scientists. All American and Japanese products were in compliance with USP 27. Since all brands were purchased commercially, and hence can be expected to be in therapeutic use, this result supports the USP 27 dissolution criterion as an indicator for therapeutic efficacy.

\section{Acknowledgments}

The authors thank Ms. Hisako Tomita, Kobe Pharmaceutical University, for experimental advice. Part of this work was supported by grants from MEXT. HAITEKU 
(2004-2008) and the Pfizer Health Care Research Foundation. The authors would also like to thank Professor Dirk Barends for his in-depth contribution and guidance on this article.

\section{References}

1. Aoyagi, N.; Kaniwa, N.; Takeda, Y.; Uchiyama, M.Jpn. Pharm. Forum 1994, 3, 46-60.

2. United States Pharmacopeia and National Formulary USP 24-NF 19; The United States Pharmacopeial Convention, Inc.: Rockville, MD, 2000; pp 856-857.

3. Approved Drug Products with Therapeutic Equivalence Evaluations, $27^{\text {th }}$ ed.; U.S. Department of Health and Human Services, Food and Drug Administration, Center for Drug Evaluation and Research, Office of Generic Drugs, U.S. Government Printing Office: Washington, DC, 2007.

4. Orange Book No.1; Society of Japanese Pharmacopoeia:Tokyo, Japan, 1999.

5. Petersen, K. U. In vitro release of felodipine from original brand and generic products. Arzneimittelforschung 2003, 53, 40-43.

6. Ministry of Health, Labour and Welfare: Pharmaceutical and Medical Safety Bureau. http:// www.mhlw.go.jp/english/org/policy/p13-14.html (accessed July 1,2007).

7. Ciffi, F. J.; Abdou, H. M.; Warren, A.T. Computerized automated system for determining dissolution rate profiles for solid dosage forms. J. Pharm. Sci. 1976, 65, 1234-1240.

8. Ciffi, F. J.; Martynovych, S.; Bendrot, H. ADS-12: An automated programmable 12-tablet dissolution testing system.J.Pharm. Sci. 1979, 68, 1280-1286.

9. Cappola, M.L.A better dissolution method for ranitidine tablets USP. Pharm. Dev. Technol. 2001,6 (1), 11-17.
10. Otsuka, M.;Tomita, H.; Otsuka, K.; Kamae, I.; Jorgenson, J. A. International Harmonization of Generic Drugs I: Comparative Study of Automatic and Manual Dissolution Tests for Japanese and American Generic Ibuprofen Tablets. Bio-Medical Mat. Eng. 2006, 16, 129-135.

11. Yanai, K. Four Steps of Excel Statistics; OMS press: Tokorozawa, Japan, 1999.

Dissolution Solutions is the one-stop
resource for pharmaceutical scientists to
catch the latest breaking news. Visit our
D-Talk forum and hear participants from the
dissolution equipment vendors, fiber optics
companies, regulatory agencies, pharma-
ceutical companies, generics, and contract
lab discussing the latest in dissolution,
equipment, and techniques. Visit special-
ized sections to find related topics on PAT,
21CFR11, HPLC, method development,
spectroscopic techniques, and other related
topics. The site also features a weekly
updated web log commenting on the
latest topics of interest. Join us at
http://www.dissolutionsolutions.net.

